\title{
Application of photochromic pigment in mass dyed polypropylene fibres intended for intelligent textiles
}

\author{
Veronika Hrabovská, Marcela Hricová, Anna Ujhelyiová \\ Slovak University of Technology in Bratislava, Faculty of Chemical and Food Technology, \\ Institute of Natural and Synthetic Polymers, Radlinskeho 9, 81237 Bratislava, Slovakia \\ veronika.hrabovska@stuba.sk
}

\begin{abstract}
At the present time, characterised by worsening environmental conditions, the protection of human organism against irreversible damage is necessary. Protective clothing on base of smart textiles represents the future in human clothing. In this article, the effect of photochromic pigments on spinnability, drawability and properties of pigmented polypropylene (PP) fibres is presented.

Mechanical properties (tenacity and elongation at break, Young's modulus), thermo-mechanical properties and the factor of average orientation of fibres were evaluated and discussed. The obtained results indicate a possibility of fibres preparation with photochromic pigments.
\end{abstract}

Keywords: polypropylene, smart polymers, mechanical properties, thermal properties, photochromic materials

\section{Introduction}

We live in an overly-technological world. Everything is advanced, modern, electronic, comfortable, but also dangerous. These dangers have been created by ourselves. On one hand, we improve our living conditions and on the other, we are worsening the living conditions on Earth. One of the impacts is the formation of the ozone hole. The ozone layer absorbs dangerous UV rays coming to Earth (Frercks at al., 2009). Solar radiation is an important natural component because it is an important factor in the Earth's climate and it has a significant impact on the environment. Ultraviolet part of the solar spectrum (UV) plays an important role in many processes in the biosphere. UV radiation has several beneficial effects but it can also be very damaging if the UV level exceeds 'safe' limits (Vikova and Vik, 2009). UV radiation has shorter wavelength and higher energy than visible light. It is an invisible part of the spectrum of electromagnetic radiation with frequencies ranging from 1012 to $1014 \mathrm{~Hz}$ and wavelengths from 4 to $400 \mathrm{~nm}$. Skin and eyes are organs with the highest exposure to sunlight UV radiation. Although hair and nails are also exposed to harmful UV radiation, they are less important from the medical point of view. UV radiation has little penetration, so protection against it is easy. Excessive exposure of human skin to the influence of UVA and UVB radiation leads to skin damage and aging, and long exposition to radiation leads to skin tumours. Only suitable clothing, gloves, glasses or sunscreen with a sufficiently high UV filter for uncovered parts of the body (Vanicek at al., 2000) can protect the body from UV radiation. Intelligent textiles with built-in UV sensitive sensors can be used in skin protection. People working in the exterior, who are exposed to sunlight, would wear garments indicating solar radiation intensity and the need for increased protection just by changing their colour intensity.

Smart textiles are specifically designed textile structures which in addition to fulfilling the functions of normal fabrics respond and react to external conditions and incentives of mechanical, electrical, chemical and radiant or heat exposure (Bamfield, 2001). According to the reaction, they can be divided into three classes: passive smart, active smart and very smart materials. Passive smart materials can only sense the environmental conditions or stimuli; active smart materials sense and react to the conditions or stimuli; very smart materials can sense, react and adapt themselves accordingly (Xiaoming, 2001).

One of the latest developments is the use of photochromic materials reacting to $\mathrm{UV}$ radiation by changing their colour. Flexibility of textile sensors and the possibility of their integration into the garment structure allow movement of the textile into which the sensor is inserted. One way of photochromic dyes application in textiles is using inkjet printing or exhaust dyeing. However, a reduction of the photochromic effect during UV-radiation exposure occurs due to photo-oxidation of photochromic dyes or washing (Dietz and El'tsov, 1990). The second way is the incorporation of photochromic pigment in polymer matrix in melt during spinning of fibres. The positive - pigment is dispersed in the mass of the fibre and is more stable during washing. These sensors, built-in textile materials 
(T-shirt, swim suit, etc.), would warn if the UV radiation reached a high value and it is time to avoid excessive exposure to the sun.

Photochromism is the reversible transformation of a chemical species from one form to another by absorption of electromagnetic radiation, where the two forms have different absorption spectra. It is simply defined as the light induced reversible change of colour (Dürr and Bouas-Laurent, 2003). The original state referred to as A and the transformed state referred to as B are both excited simultaneously but the prevalent state depends on the electromagnetic radiation (Crano and Guglielmetti, 1999; Bouas-Laurent and Dürr, 2001). Simple photochromic processes can be described as described in Fig. 1.

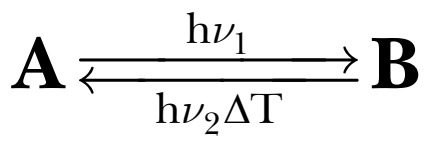

Fig. 1. Scheme of a simple photochromic process (Vikova, 2009).

Photochromic compounds can be divided into five main classes: spiropyrans (spiroindolinobenzopyrans), spironaphtoxazines, naphtopyrans (chromenes), fulgides and diarylethenes. In terms of applicability to textile fibres, spiropyrans, spironaphtoxazines and chromenes have been found as the most suitable ones considering fatigue, life time and fastness properties (Durasevic at al., 2011). Based on the photochromic pigment, a simple textile sensor sensitive to UV radiation for visual identification of UV radiation has been developed. At present, there is a large number of photochemical dyes. To indicate the photochromic potential, these dyes have to be embedded in the matrix. Technically and economically most important matrices are polymers, especially thermoplastics. Photochromic functionalized polymers have specific characteristics and thus they are very sensitive to their environment - structure of polymer matrix or degradation of products and additives. Therefore, parameters of photochromic reactions such as speed, intensity, spectral distribution of colour change and fatigue phenomenon after prolonged UV irradiation could be used as matrix state sensors (Nechwatal and Nicolai, 2011).

\section{Experimental part}

\section{Materials used}

For the preparation of fibres, polypropylene Metocene HM562R (PP) from LyondellBasell Industries, c.o., Italy, was used. The characteristics of PP:

- melt flow rate $\mathrm{MFR}=25 \mathrm{~g} / 10 \mathrm{~min}\left(230^{\circ} \mathrm{C} / 2.016 \mathrm{~kg}\right)$

- melting temperature $\operatorname{Tm}(\mathrm{DSC})=145^{\circ} \mathrm{C}$
In the experimental part of the work, commonly available photochromic pigments Photopia ${ }^{\circledR}$ Aqualite Ink Purple AQ-R (PURPLE) from Matsui Shikiso Chemical Co.,Ltd., Japan, were used. These pigments are able to change their colour with sunlight or ultraviolet light. The photochromic pigments are in form of paste containing 30-50 wt. \% of photochromic microcapsules.

\section{Preparation of fibres}

PP granules were mixed with photochromic pigments in form of paste in two ways. In the first one, the photochromic pigment was directly added to the PP granules and mechanically mixed. In the second one, the photochromic pigment was at first dissolved in a small amount of ethanol (EtOH), and then added to the PP granules. The amount of pigment added corresponded to the final concentration in the fibres. Concentrations of photochromic paste in the fibres were $0.5 ; 1 ; 1.5 ; 2$ and 3 wt. \%. The next step of prepared mixtures processing consisted in drying for one hour with occasional mixing at the drying temperature of $50{ }^{\circ} \mathrm{C}$. Pigmented PP fibres were prepared by spinning of the blend using a laboratory spinning plant at the spinning temperature of $220^{\circ} \mathrm{C}$ for all prepared samples. Then, the fibres were drawn using a laboratory drawing machine at mutual draw ratios $\lambda=3$ and maximal draw ratios, $\lambda_{\max }$, at the drawn temperature of $120^{\circ} \mathrm{C}$.

\section{Methods used}

Rheological properties of polymer melt: Rheological properties of the polymer blends were measured using a capillary extrusiometer Göttfert N 6967 with extruder $\phi$ of $20 \mathrm{~mm}$ at $220^{\circ} \mathrm{C}$. Measurement conditions were close to those in the spinning equipment, namely dynamic conditions in the extruder before blended melt extrusion. The Newton and Oswald de Waele laws for basic rheological parameters determination: apparent viscosity, $\eta$, and power law index, $n$, which characterize the non-Newtonian behaviour of the polymer melt, were used:

$$
\begin{gathered}
\eta=\tau / \gamma^{\cdot} \\
\left(\tau=k \gamma^{\cdot \mathrm{n}}\right)
\end{gathered}
$$

where $\tau-$ shear stress, $\gamma^{*}$ - shear rate, $\eta$ - apparent viscosity, $n$ - power law index, $k$ - coefficient.

Mechanical properties: Mechanical properties (tenacity and elongation at break, Young's modulus) of PP and pigmented PP fibres were evaluated. The Instron (Type 3343) was used to measure the mechanical properties according to ISO 2062:1993 from 15 measurements. Initial length was $125 \mathrm{~mm}$ and the deformation time was about 20 s. Mechanical properties (tenacity and elongation at break, Young's 
modulus) and their coefficients of variations were evaluated by the Instron Software Series IX.

Thermo-mechanical properties: Thermo-mechanical characteristics of PP and pigmented PP fibres were measured by a Schimadzu TMA 50. Deformation (extension or shrinkage) of fibres at constant load in the temperature range of $30-100{ }^{\circ} \mathrm{C}$ (heating speed of $5^{\circ} \mathrm{C} / \mathrm{min}$.) were evaluated. The length of fibres was $9.8 \mathrm{~mm}$.

Thermal properties: Thermal properties were measured by DSC $1 / 750$ with a ceramic sensor FRS5 by the SW STARe software from Metler Toledo. Conditions used for the measurement were: 1 . heating: $50-220^{\circ} \mathrm{C}$, cooling: $220-50{ }^{\circ} \mathrm{C}$, 2. heating: $50-220^{\circ} \mathrm{C}$. The speed of heating or cooling was $10^{\circ} \mathrm{C} / \mathrm{min}$ and the measurements were made in inert nitrogen atmosphere. Glass temperature $\left(T_{g}\right)$, melting temperature $\left(T_{m}\right)$ and melting enthalpy $\left(\Delta H_{m}\right)$ were determined.

Orientation of fibres: The speed of sound in PP and pigmented PP fibres was measured by the Dynamic Modulus Tester PPM-SR and it was used according to standard PND 129-126-06. Factor of average orientation $\left(f_{\alpha}\right)$ of fibres was calculated by measuring the speed of sound in oriented fibres:

$$
f_{\alpha}=1-\frac{c_{n}^{2}}{c^{2}}
$$

where: $f_{\alpha}$ - factor of average orientation of fibres, $c_{n}-$ speed of sound in non-oriented fibres $\left[\mathrm{km} \cdot \mathrm{s}^{-1}\right]$, $c$ - speed of sound in fibres $\left[\mathrm{km} \cdot \mathrm{s}^{-1}\right]$.

\section{Results and discussion}

Rheological properties of PP and PP/PURPLE blends Rheological properties of polymer melts provide information about their behaviour, conditions of shear and elongation flow and the processing conditions. Rheological properties of polymer blends were measured to monitor the impact of the photochromic pigment content on the PP/PURPLE melts processability. The melt flow properties of PP and PP compositions were evaluated at different concentrations of photochromic pigments $(0.5,1,1.5,2$, and 3 wt. \%) prepared with EtOH or mechanically at $220^{\circ} \mathrm{C}$.

The results showed no influence of photochromic pigments on the rheological properties of PP melt nor on the PP/PURPLE blends preparation. Dependencies of shear stress, $\tau_{s}$, on shear rate, $\gamma$; for all PP/PURPLE samples prepared with EtOH or mechanically are almost identical with those of pure PP (Figures 2, 3). Values of the power law index, $n$, and viscosity, $\eta$, of PP and PP/PURPLE blends are very similar and these samples are characterized by good processability (Tables 1, 2).

\section{Mechanical properties of PP and PP/PURPLE fibres} The aim of this work was to prepare PP fibres containing photochromic pigment with suitable mechanical properties. The effect of fibres preparation and photochromic pigments concentration were evaluated.

Tab. 1. Power law index, $n$, and viscosity, $\eta$, of $P P$ and $P P / P U R P L E$ blends prepared mechanically at $220{ }^{\circ} \mathrm{C}$.

\begin{tabular}{|c|c|c|c|c|}
\hline \multirow{2}{*}{ composition } & \multirow{2}{*}{$n$} & \multicolumn{3}{|c|}{$\eta[$ Pa.s $]$} \\
\hline & & $\gamma^{\cdot}=300 \mathrm{~s}^{-1}$ & $\gamma^{\cdot}=500 \mathrm{~s}^{-1}$ & $\gamma^{\cdot}=1000 \mathrm{~s}^{-1}$ \\
\hline PP $562 \mathrm{R}$ & 0.41 & 217 & 161 & 107 \\
\hline PP+0.5 \% PURPLE mech. & 0.42 & 214 & 159 & 106 \\
\hline PP+1 \% PURPLE mech. & 0.41 & 216 & 159 & 105 \\
\hline PP+1.5 \% PURPLE mech. & 0.41 & 216 & 160 & 106 \\
\hline PP+2 \% PURPLE mech. & 0.41 & 217 & 160 & 106 \\
\hline PP+3 \% PURPLE mech. & 0.41 & 217 & 160 & 106 \\
\hline
\end{tabular}

Tab. 2. Power law index, $n$, and viscosity, $\eta$, of $P P$ and $P P / P U R P L E$ blends prepared with EtOH at $220^{\circ} \mathrm{C}$.

\begin{tabular}{|c|c|c|c|c|}
\hline \multirow{2}{*}{ composition } & \multirow{2}{*}{$n$} & \multicolumn{3}{|c|}{$\eta[\mathbf{P a} \cdot \mathbf{s}]$} \\
\hline & & $\gamma^{\cdot}=300 \mathrm{~s}^{-1}$ & $\gamma^{\cdot}=500 \mathrm{~s}^{-1}$ & $\gamma^{\cdot}=1000 \mathrm{~s}^{-1}$ \\
\hline PP $562 \mathrm{R}$ & 0.41 & 217 & 161 & 107 \\
\hline $\mathrm{PP}+0.5 \%$ PURPLE EtOH & 0.40 & 219 & 161 & 106 \\
\hline $\mathrm{PP}+1 \%$ PURPLE EtOH & 0.41 & 215 & 159 & 106 \\
\hline $\mathrm{PP}+1.5 \%$ PURPLE EtOH & 0.41 & 217 & 160 & 106 \\
\hline $\mathrm{PP}+2 \%$ PURPLE EtOH & 0.41 & 218 & 161 & 106 \\
\hline $\mathrm{PP}+3 \%$ PURPLE EtOH & 0.40 & 216 & 159 & 110 \\
\hline
\end{tabular}




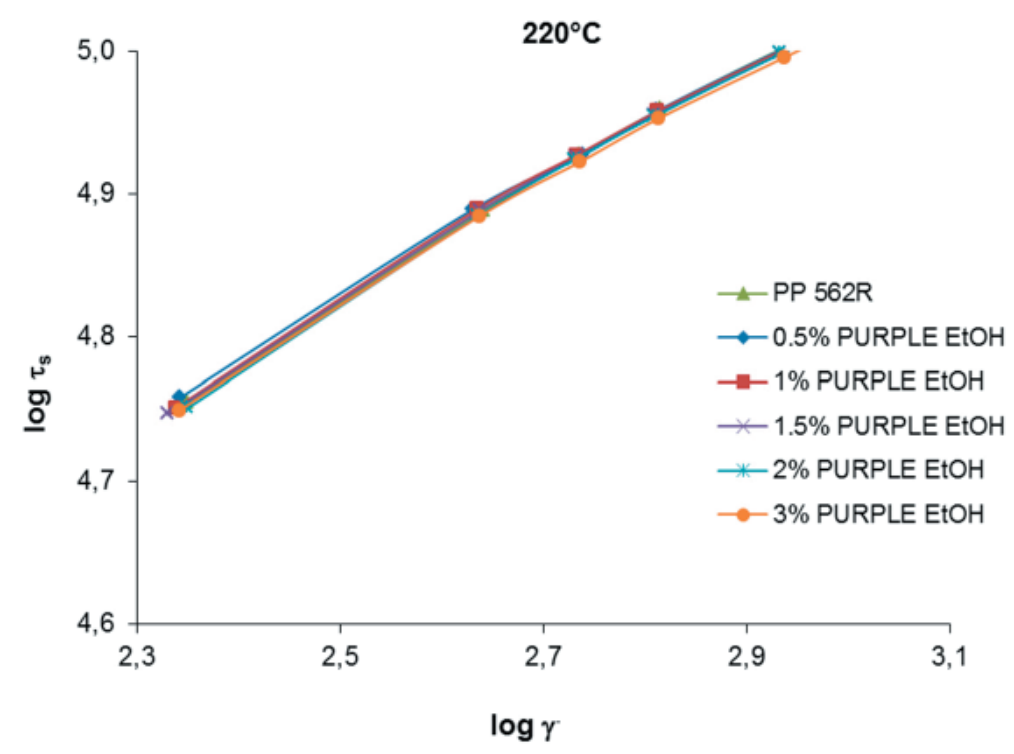

Fig. 2. Flow curves of $P P$ and samples $P P / P U R P L E$ EtOH with all concentrations of photochromic paste.

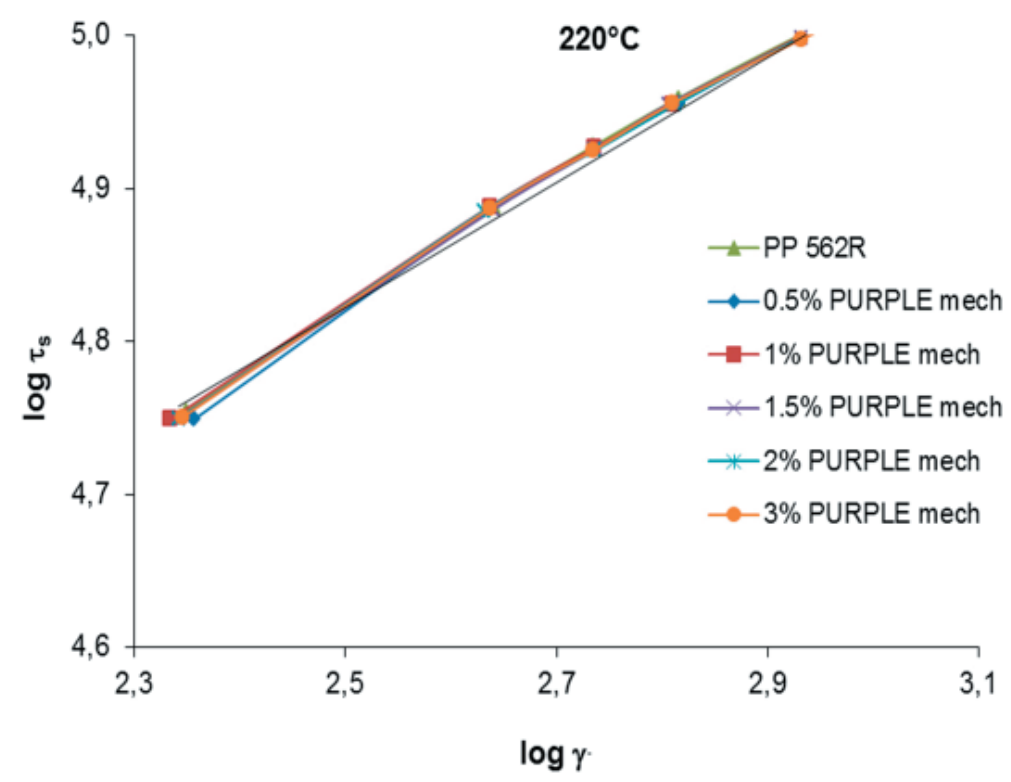

Fig. 3. Flow curves of $P P$ and $P P / P U R P L E m e c h$. samples mixed with all studied photochromic paste concentrations.

All prepared fibres were drawn at maximal draw ratio, $\lambda_{\max }$, and one mutual drawn ratio, $\lambda_{3}$. Samples of PP fibres containing 3 wt. \% of photochromic paste were prepared with minor problems. However, PP $+3 \%$ of PURPLE EtOH were not able to spin at all.

Fibres from the PP/PURPLE mech. series drawn at $\lambda_{3}$ showed improved tenacity at break at the concentration of $0.5 \mathrm{wt}$ \% compared to pure PP. Higher concentration of photochromic pigment in fibres, 1-3 wt. \%, improved the tenacity of break, but no effect of the increasing photochromic pigment concentration in fibres was observed. Tenacity at break was $19.0-19.3 \mathrm{cN} /$ tex with the exception of
PP $+2 \%$ PURPLE where it was $18.2 \mathrm{cN} /$ tex, which is lower than for other pigmented fibres but still higher than for pure PP.

Fibres from the PP/PURPLE mech. series drawn at $\lambda_{\max }$ showed no significant effect of the increasing photochromic pigment concentration on the tenacity values. All fibres showed lower tenacity at break compared to PP with the exception of fibres concentration of $1.5 \mathrm{wt}$. \%. Homogeneity of the polymer mass with photochromic pigment and pigment distribution in fibres were low because they were not prepared from polymer concentrate but by mechanical mixing of polymer granules and photochromic pigment before spinning. This assump- 
tion is supported also by high values of structural non-uniformity of mechanical properties according to their variation coefficients. Very similar dependences were also shown for the Young's modulus PP/ PURPLE mech. fibres (Tables 3 and 4).

Fibres from the PP/PURPLE mech. series drawn at $\lambda_{3}$ showed higher values of elongation at break compared to pure PP. No significant dependence on the increasing photochromic pigment concentration and the elongation at break was observed. Fibres with the photochromic pigment content of $0.5 ; 1.5$ and 3 wt. \% have very similar values of elongation at break (70-72 \%). PP + $1 \%$ PURPLE fibres show low elongation at break (54\%) and also low tenacity at break compared with other pigmented fibres. Photochromic pigment concentration of 2 wt. \% caused significant increase of elongation at break $(81 \%)$.

For PP/PURPLE EtOH fibres drawn at $\lambda_{3}$, the tenacity at break decreased to $18.2 \mathrm{cN} /$ tex $(\mathrm{PP}+1 \%$ PURPLE EtOH); for the highest photochromic pigment concentration ( $\mathrm{PP}+2 \% \mathrm{PURPLE} \mathrm{EtOH})$ is the tenacity at break the highest (Table 5 and 6).

For all PP/PURPLE EtOH fibres drawn at $\lambda_{\max }$, with the increasing concentration of photochromic pigment, the values of tenacity at break and Young's modulus decrease as confirmed by the decreasing value of the maximal drawn ratio compared with pure PP. Conversely, values of elongation at break are higher than for pure PP. Higher values of elongation at break were measured for fibres with 1 and 1.5 wt. \% of photochromic pigment. For no PP/PURPLE EtOH $\left(\lambda_{3}\right.$ and $\left.\lambda_{\max }\right)$ sample, dependence between the increasing photochromic pigment concentration and values of elongation at break for the prepared fibres was observed.

Non-uniformity of the fibres mechanical properties, such as tenacity and elongation at break and Young's modulus, results from the non-uniformity of the fibre macrostructure, the number of weaknesses, macro and micro defects of individual filaments, non-uniformity of the fibres cross section, and the non-uniformity of molecular, supramolecular and morphological structures. It is a realistic assumption that the cumulative effect of these variables is reflected in fibre deformation. The variation coefficients show the non-uniformity of PP fibres containing PURPLE photochemical pigment (Tables 3-6).

\section{Thermo-mechanical properties of PP and PP/ PURPLE fibres}

Figures 4 and 5 provide graphical presentation of dimensional stability (deformation) for PP and PP/PURPLE fibres and the effect of photochromic pigment content and the preparation procedure on the deformation of these fibres in dependence on temperature in the defined temperature mode. Dimensional stability (deformation) of all fibres by their shrinkage is shown.

Tab. 3. Tenacity, $\sigma$, and elongation at break, $\varepsilon$, Young's modulus, $E$, and their coefficients of variation for $P P$ and $P P / P U R P L E$ mech fibres drawn at $\lambda_{\max }$.

\begin{tabular}{lccccccc}
\hline Fibre & $\lambda_{\max }$ & $\begin{array}{c}\sigma \\
{[\mathbf{c N} / \mathbf{t e x}]}\end{array}$ & $\begin{array}{c}\mathbf{C V} \boldsymbol{\sigma} \\
{[\%]}\end{array}$ & $\begin{array}{c}\varepsilon \\
{[\%]}\end{array}$ & $\begin{array}{c}\mathbf{G V} \boldsymbol{\varepsilon} \\
{[\%]}\end{array}$ & $\begin{array}{c}\boldsymbol{E} \\
{[\mathbf{N} / \mathbf{t e x}]}\end{array}$ & $\begin{array}{c}\mathbf{C V}_{\mathbf{E}} \\
{[\%]}\end{array}$ \\
\hline PP 562R & 4.8 & 25.8 & 5.6 & 46 & 15.1 & 2.90 & 8.7 \\
PP + 0.5 \% PURPLE mech. & 3.8 & 22.9 & 10.9 & 70 & 10.8 & 2.31 & 10.2 \\
PP + 1 \% PURPLE mech. & 3.5 & 18.2 & 9.1 & 54 & 10.3 & 1.88 & 11.7 \\
PP + 1.5 \% PURPLE mech. & 4.0 & 26.9 & 12.2 & 71 & 13.8 & 2.70 & 17.0 \\
PP + 2 \% PURPLE mech. & 3.5 & 22.8 & 13.6 & 81 & 10.0 & 2.31 & 6.0 \\
PP + 3 \% PURPLE mech. & 3.5 & 24.2 & 9.3 & 72 & 10.7 & 2.21 & 4.8 \\
\hline
\end{tabular}

Tab. 4. Tenacity, $\sigma$, and elongation at break, $\varepsilon$, Young's modulus, $E$, and their coefficients of variation for $P P$ and $P P / P U R P L E$ mech fibres drawn at $\lambda_{3}$.

\begin{tabular}{lccccccc}
\hline Fibre & $\boldsymbol{\lambda}$ & $\begin{array}{c}\boldsymbol{\sigma} \\
{[\mathbf{c N} / \mathbf{t e x}]}\end{array}$ & $\begin{array}{c}\mathbf{C V} \boldsymbol{\sigma} \\
{[\%]}\end{array}$ & $\begin{array}{c}\boldsymbol{\varepsilon} \\
{[\%]}\end{array}$ & $\begin{array}{c}\mathbf{C V} \boldsymbol{\varepsilon} \\
{[\%]}\end{array}$ & $\begin{array}{c}\boldsymbol{E} \\
{[\mathbf{N} / \mathbf{t e x}]}\end{array}$ & $\begin{array}{c}\mathbf{C V}_{\mathbf{E}} \\
{[\%]}\end{array}$ \\
\hline PP 562R & 3.0 & 17.2 & 10.7 & 126 & 10.3 & 1.40 & 15.0 \\
PP + 0.5 \% PURPLE mech. & 3.0 & 20.0 & 12.5 & 101 & 14.8 & 1.83 & 12.3 \\
PP + 1 \% PURPLE mech. & 3.0 & 19.0 & 14.6 & 100 & 10.7 & 1.62 & 9.8 \\
PP + 1.5 \% PURPLE mech. & 3.0 & 19.3 & 7.8 & 98 & 10.5 & 1.69 & 11.7 \\
PP + 2 \% PURPLE mech. & 3.0 & 18.2 & 8.9 & 80 & 10.2 & 1.63 & 10.7 \\
PP + 3 \% PURPLE mech. & 3.0 & 19.2 & 9.9 & 87 & 8.6 & 1.55 & 4.6 \\
\hline
\end{tabular}


Tab. 5. Tenacity, $\sigma$, and elongation at break, $\varepsilon$, Young's modulus, $E$, and their coefficients of variation for $P P$ and PP/PURPLE EtOH fibres drawn at $\lambda_{\max }$.

\begin{tabular}{lccccccc}
\hline Fibre & & $\begin{array}{c}\sigma \\
\lambda_{\max }\end{array}$ & $\begin{array}{c}\mathrm{CV} \sigma \\
{[\mathrm{cN} / \mathrm{tex}]}\end{array}$ & $\begin{array}{c}\varepsilon \\
{[\%]}\end{array}$ & $\begin{array}{c}\mathrm{CV} \varepsilon \\
{[\%]}\end{array}$ & $\begin{array}{c}E \\
{[\mathrm{~N} / \mathrm{tex}]}\end{array}$ & $\begin{array}{c}\mathrm{CV}_{\mathrm{E}} \\
{[\%]}\end{array}$ \\
\hline PP 562R & 4.8 & 29.6 & 4.1 & 38 & 12.3 & 3.19 & 6.8 \\
PP + 0.5 \% PURPLE EtOH & 4.2 & 27.1 & 10.4 & 58 & 7.4 & 2.66 & 10.4 \\
PP + 1 \% PURPLE EtOH & 3.7 & 21.5 & 12.0 & 69 & 13.4 & 2.22 & 14.7 \\
PP + 1.5 \% PURPLE EtOH & 3.4 & 19.1 & 10.6 & 67 & 9.8 & 1.79 & 16.3 \\
PP + 2 \% PURPLE EtOH & 3.2 & 13.9 & 23.9 & 60 & 11.7 & 1.51 & 11.2 \\
PP + 3 \% PURPLE EtOH & 1.0 & - & - & - & - & - & - \\
\hline
\end{tabular}

Tab. 6. Tenacity, $\sigma$, and elongation at break, $\varepsilon$, Young's modulus, $E$, and their coefficients of variation for $P P$ and PP/PURPLE EtOH fibres drawn at $\lambda_{3}$.

\begin{tabular}{lccccccc}
\hline Fibre & $\lambda$ & $\begin{array}{c}\sigma \\
{[\mathrm{cN} / \mathrm{tex}]}\end{array}$ & $\begin{array}{c}\mathrm{CV} \sigma \\
{[\%]}\end{array}$ & $\begin{array}{c}\varepsilon \\
{[\%]}\end{array}$ & $\begin{array}{c}\mathrm{CV} \varepsilon \\
{[\%]}\end{array}$ & $\begin{array}{c}E \\
{[\mathrm{~N} / \mathrm{tex}]}\end{array}$ & $\begin{array}{c}\mathrm{CV}_{\mathrm{E}} \\
{[\%]}\end{array}$ \\
\hline PP 562R & 3.0 & 19.9 & 10.7 & 115 & 12.3 & 1.55 & 9.3 \\
PP+0.5 \% PURPLE EtOH & 3.0 & 17.7 & 7.7 & 100 & 9.8 & 1.51 & 9.6 \\
PP+1 \% PURPLE EtOH & 3.0 & 16.4 & 22.0 & 78 & 8.9 & 1.67 & 17.7 \\
PP+1.5 \% PURPLE EtOH & 3.0 & 15.9 & 11.2 & 81 & 15.3 & 1.51 & 16.1 \\
PP+2 \% PURPLE EtOH & 3.0 & 21.5 & 8.1 & 91 & 11.5 & 1.91 & 13.7 \\
PP+3 \% PURPLE EtOH & 1.0 & - & - & - & - & - & - \\
\hline
\end{tabular}

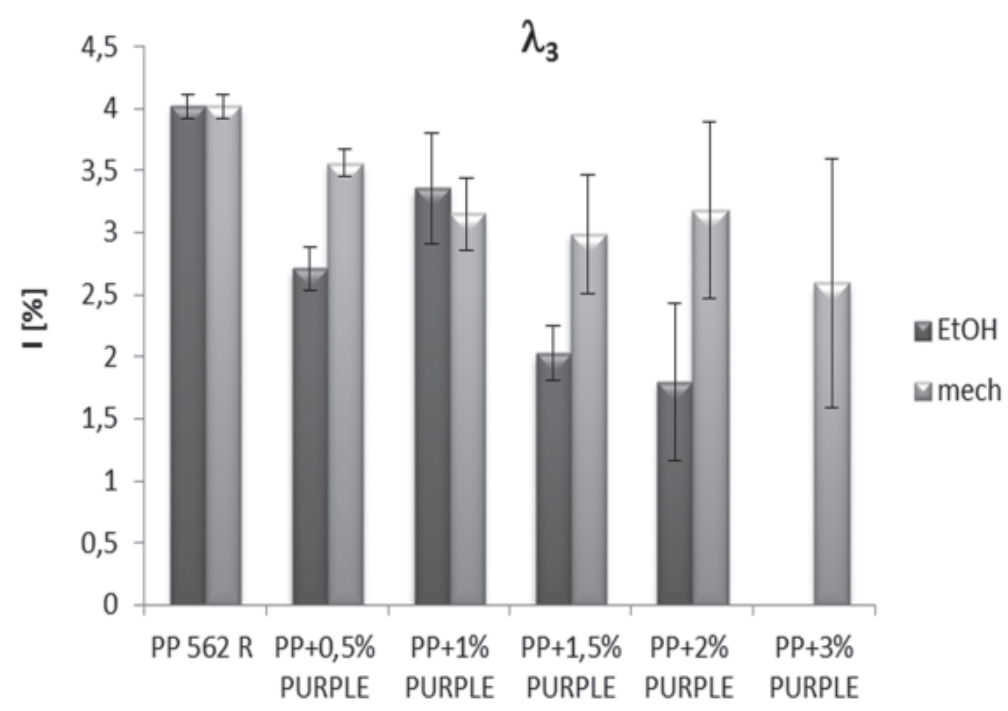

Fig. 4. Dependence of deformation - shrinkage $l[\%]$ of $P P$ and PP/PURPLE fibres drawn at $\lambda_{3}$ on photochromic pigment concentration.

PP/PURPLE fibres drawn at $\lambda_{3}$ showed lower deformation and thereby better dimensional stability as pure PP fibres (Figure 4). Deformation of PP/ PURPLE mech. fibres is almost the same and that of PP/PURPLE EtOH fibres, which decreases with the pigment content, is significantly lower. An exception are fibres with pigment concentration of 1 wt. \%, which showed higher deformation probably due to higher pigment concentration in fibres causing an increase of the PP temperature resistance.
PP/PURPLE fibres drawn at $\lambda_{\max }$ showed higher deformation as pure PP fibres (Figure 5) which can be a result of the action of internal stresses created during the orientation by spinning and drawing. PP/PURPLE EtOH fibres drawn at $\lambda_{\max }$ showed a very similar deformation. The exception are fibres with pigment concentration of 1 wt. \%, which showed the highest deformation. For PP/PURPLE mech. drawn at $\lambda_{\max }$, the deformation is different as it is not dependt on the pigment content. For 


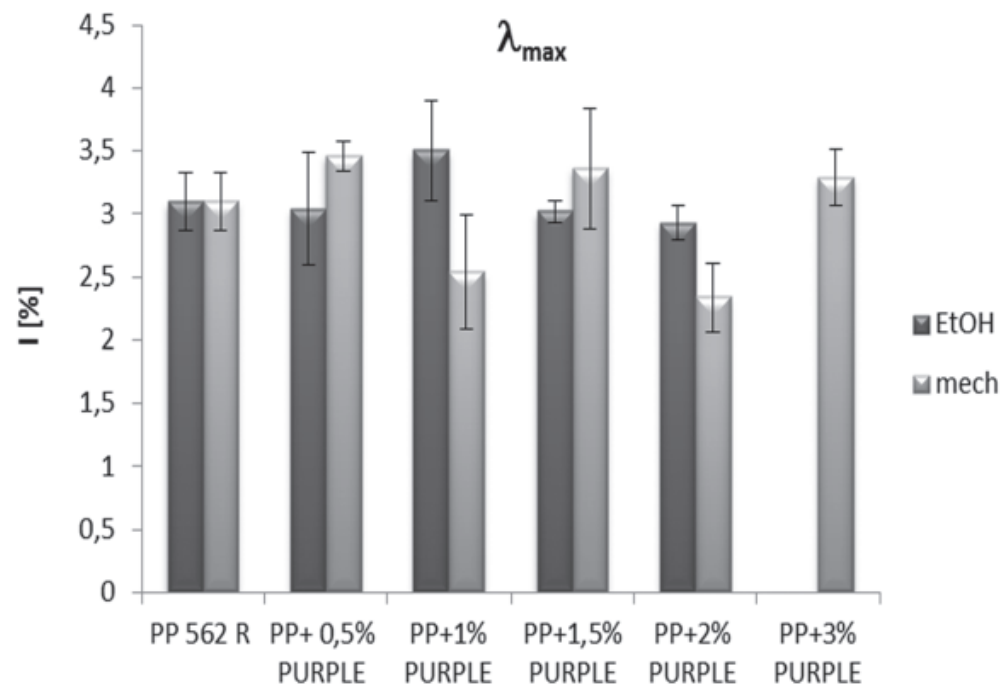

Fig. 5. Dependence of deformation - shrinkage $l[\%]$ of $P P$ and PP/PURPLE fibres drawn at $\lambda_{\max }$ on photochromic pigment concentration.

fibres with pigment concentration of 0.5 wt. \%, the highest deformation was found while lower deformation was determined for fibres with pigment concentration of $1 \mathrm{wt}$ \% and 2 wt. \% compared to pure PP fibres.

From the results in Tables 7 and 8 it can be seen that the concentration of photochromic pigment does not significantly affect the deformation temperature of PP and PP/PURPLE fibres drawn at $\lambda_{\max }$. The

Tab. 7. Temperature of deformation of $P P$ and PP/PURPLE fibres drawn at $\lambda_{3}$.

\begin{tabular}{lcc}
\hline \multirow{2}{*}{ Fibre } & \multicolumn{2}{c}{$\boldsymbol{T}\left[{ }^{\circ} \mathbf{C}\right]$} \\
\cline { 2 - 3 } & EtOH & mech. \\
\hline PP 562R & 65.9 & 65.9 \\
PP + 0.5 \% PURPLE & 72.3 & 56.8 \\
PP + 1 \% PURPLE & 60.1 & 67.9 \\
PP + 1.5 \% PURPLE & 65.7 & 64.6 \\
PP + 2 \% PURPLE & 53.8 & 58.7 \\
PP + 3 \% PURPLE & - & 57.6 \\
\hline
\end{tabular}

Tab. 8. Temperature of deformation of $P P$ and PP/PURPLE fibres drawn at $\lambda_{\max }$.

\begin{tabular}{lcc}
\hline \multirow{2}{*}{ Fibre } & \multicolumn{2}{c}{$\boldsymbol{T}\left[{ }^{\circ} \mathbf{C}\right]$} \\
\cline { 2 - 3 } & EtOH & mech. \\
\hline PP 562R & 55.2 & 55.2 \\
PP + 0.5 \% PURPLE & 57.1 & 55.5 \\
PP + 1 \% PURPLE & 57.1 & 68.0 \\
PP + 1.5 \% PURPLE & 53.7 & 62.3 \\
PP + 2 \% PURPLE & 56.4 & 61.9 \\
PP + 3 \% PURPLE & - & 59.3 \\
\hline
\end{tabular}

highest temperature of deformation was determined for PP/PURPLE EtOH fibres with 0.5 wt. \% of photochromic paste drawn at $\lambda_{3}$ while PP/PURPLE mech. fibres with the same concentration showed the lowest temperature of deformation.

\section{Thermal properties}

Thermal properties from the first heating show the effect of fibres processing and polymer mixing with pigment (Tables 9 and 10). Thermal properties were measured only for fibres drawn at the maximal drawn ratio, $\lambda_{\max }$.

Fibres prepared by mechanical mixing of the pigment with polymer have lower $T_{m 1}$ than pure PP, except for PP $+1.5 \%$ PURPLE fibres with the highest $T_{m 1}$ (Table 9). Fibres prepared by mixing of polymer with pigment in form of photochromic paste dissolved in a small amount of ethanol have higher $T_{m 1}$ values for pigment concentration of 1 wt. $\%$ and 1.5 wt. \% than pure PP (Table 10). Melting temperature, $T_{m 2}$, of all PP/PURPLE fibres is almost the same. No significant effect of the increasing photochromic pigment concentration. The pigment in the polymer has no nucleation effect, which results from constant $T_{m 2}$ value for the whole concentration range of pigment in polymer, regardless of the fibre preparation method.

Melting enthalpy of the first heating is slightly higher for PP/PURPLE mech. fibres compared to the PP/PURPLE EtOH fibres. Higher $\Delta H_{m}$ means higher crystalline portion in the fibres compared to non-oriented polymer. At the second heating, higher enthalpy was found for pigment concentration of $1-1.5$ wt. \% for both preparation methods (Tables 9 and 10). 
Tab. 9. Melting temperature, $T_{m}$, and melting enthalpy, $\triangle H_{m}$, of $P P$ and $P P / P U R P L E$ mech. fibres drawn at $\lambda_{\max }$.

\begin{tabular}{lcccc}
\hline \multirow{2}{*}{ Fibre } & \multicolumn{2}{c}{ first heating } & \multicolumn{2}{c}{ second heating } \\
\cline { 2 - 5 } & $\boldsymbol{T}_{m 1}\left[{ }^{\circ} \mathbf{C}\right]$ & $\Delta \boldsymbol{H}_{m 1}\left[\mathrm{~J} \cdot \mathbf{g}^{-1}\right]$ & $\boldsymbol{T}_{m 2}\left[{ }^{\circ} \mathbf{C}\right]$ & $\Delta \boldsymbol{H}_{m 2}\left[\mathrm{~J} \cdot \mathbf{g}^{-1}\right]$ \\
\hline PP 562R & 147.4 & 81.6 & 144.4 & 78.0 \\
PP + 0.5 \% PURPLE mech. & 146.2 & 86.4 & 144.0 & 76.0 \\
PP + 1 \% PURPLE mech. & 146.3 & 77.2 & 144.2 & 76.5 \\
PP + 1.5 \% PURPLE mech. & 147.6 & 80.3 & 144.2 & 80.1 \\
PP + 2 \% PURPLE mech. & 146.3 & 79.1 & 144.4 & 77.6 \\
PP + 3 \% PURPLE mech. & 147.0 & 75.9 & 144.8 & 77.5 \\
\hline
\end{tabular}

Tab. 10. Melting temperature, $T_{m}$, and melting enthalpy, $\triangle H_{m}$, of $P P$ and $P P / P U R P L E E t O H$ fibres drawn at $\lambda_{\max }$

\begin{tabular}{lcccc}
\hline \multirow{2}{*}{ Fibre } & \multicolumn{2}{c}{ first heating } & \multicolumn{2}{c}{ second heating } \\
\cline { 2 - 5 } & $\boldsymbol{T}_{m 1}\left[{ }^{\circ} \mathbf{C}\right]$ & $\boldsymbol{\Delta} \boldsymbol{H}_{m 1}\left[\mathrm{~J} \cdot \mathbf{g}^{-1}\right]$ & $\boldsymbol{T}_{m 2}\left[{ }^{\circ} \mathbf{C}\right]$ & $\Delta \boldsymbol{H}_{m 2}\left[\mathrm{~J} \cdot \mathbf{g}^{-1}\right]$ \\
\hline PP 562R & 147.4 & 81.6 & 144.4 & 78.0 \\
PP + 0.5 \% PURPLE EtOH & 147.3 & 76.1 & 144.2 & 75.1 \\
PP + 1 \% PURPLE EtOH & 148.1 & 77.6 & 144.7 & 82.5 \\
PP + 1.5 \% PURPLE EtOH & 148.4 & 77.6 & 144.5 & 83.4 \\
PP + 2 \% PURPLE EtOH & 146.0 & 69.6 & 144.3 & 76.1 \\
PP + 3\% PURPLE EtOH & - & - & - & - \\
\hline
\end{tabular}

\section{Orientation of fibres}

Average orientation of fibres is determined by the speed of sound method and consequently by calculating the factor of average orientation, $f_{\alpha}$.

Tab. 11. Factor of average orientation, $f_{\alpha}$, of $P P$ and $P P / P U R P L E$ fibres drawn at $\lambda_{\max }$.

\begin{tabular}{lcc}
\hline \multirow{2}{*}{ Fibre } & \multicolumn{2}{c}{$f_{\alpha}$} \\
\cline { 2 - 3 } & EtOH & mech. \\
\hline PP 562R & 0.715 & 0.715 \\
PP + 0.5 \% PURPLE & 0.698 & 0.670 \\
PP + 1 \% PURPLE & 0.673 & 0.652 \\
PP + 1.5 \% PURPLE & 0.626 & 0.708 \\
PP + 2 \% PURPLE & 0.622 & 0.692 \\
PP + 3 \% PURPLE & - & 0.653 \\
\hline
\end{tabular}

Tab. 12. Factor of average orientation, $f_{\alpha}$, of $P P$ and PP/PURPLE fibres drawn at $\lambda_{3}$.

\begin{tabular}{lcc}
\hline \multirow{2}{*}{ Fibre } & \multicolumn{2}{c}{$f_{\alpha}$} \\
\cline { 2 - 3 } & EtOH & mech. \\
\hline PP 562R & 0.574 & 0.574 \\
PP + 0.5 \% PURPLE & 0.566 & 0.671 \\
PP + 1\% PURPLE & 0.595 & 0.599 \\
PP + 1.5 \% PURPLE & 0.663 & 0.628 \\
PP + 2\% PURPLE & 0.564 & 0.622 \\
PP + 3\% PURPLE & - & 0.613 \\
\hline
\end{tabular}

Values of the factor of average orientation measured for PP/PURPLE fibres drawn at $\lambda_{\max }$ are almost the same for both series of prepared fibres and they are in the range of $0.6-0.72$ (Tables 11). The best orientation was found for pure PP fibres, which corresponds to the highest drawn ratio, $\lambda_{\max }$. A similar value of the factor of average orientation was determined for a sample with the photochromic paste concentration of $1.5 \%$, which agrees with the mechanical properties of these fibres and provides the most optimal pigment concentration in PP. For a mutual drawn ratio, $\lambda_{3}$, factors of average orientation are lower, probably because of the insufficiently drawn fibres at this ratio and thus their insufficient orientation (Table 12).

\section{Conclusions}

Experimental part of the present work has confirmed that it is possible to prepare PP fibres containing photochromic pigment in their mass and that these fibres show satisfying mechanical properties.

Two series of fibres containing photochromic pigments, which differ in the PP granulate and photochromic pigment mixing procedure, were prepared. Rheological properties of PP melt containing photochromic pigment showed that the photochromic pigment does not significantly affect the PP flow properties. Another goal of the 
experiment was to evaluate the properties of prepared fibres. From the results obtained it cannot be clearly determined which method of pigmented PP fibres preparation is more advantageous. Dimensional stability of all fibres was manifested by their shrinkage. Fibres drawn at $\lambda_{3}$ showed lower deformation and thus better dimensional stability than fibres drawn at $\lambda_{\max }$. Concentration of photochromic pigment in the mass of PP fibres does not significantly affect their deformation temperature. No significant effect of photochromic pigment concentration increase or the preparation method used on the factor of average orientation was observed. Properties of these fibres can be improved in future by optimizing the PP fibre preparation, conditions in the pigment blending process and spinning process.

\section{Acknowledgement}

This work was supported by the Slovak Research and Development Agency under the contract No: APVV-14-0175.

\section{References}

Bamfield P (2001) Chromic phenomena: The technological applications of colour chemistry. Cambridge, UK: The Royal Society of Chemistry.

Bouas-Laurent H, Dürr H (2001) Organic photochromism. Pure and Applied Chemistry, 73(4): 639-665.

Crano JC, Guglielmetti RJ (Ed) (1999) Organic photochromic and thermochromic compounds: Volume 1: Main Photochromic Families, New York, USA: Kluwer Academic Publishers.
Dietz F, El'tsov AV (1990) Theoretical studies of the photochromism of organic compounds. In: Organic Photochromes. Boston, MA: Springer.

Durasevic V, Osterman PD, Sutlovic A (2011) From Murex Purpura to sensory - photochromic textiles. In Prof. Peter Hauser (Ed.), Textile Dyeing (pp. 57-76). InTech.

Dürr H, Bouas-Laurent H (2003) Photochromism: Moleculs and Systems, Elsevier Science.

Frercks J, Weber H, Wiesenfeldt G (2009) Reception and discovery: the nature of Johann Wilhelm Ritter's invisible rays. Studies in History and Philosophy of Science, Part A, 40(2): 143-156.

Nechwatal A, Nicolai M (2011) Interactions between polypropylene and photochromic dyestuffs. Polymer Degradation and Stability, 96: 1648-1652.

Vanicek K, Frei T, Litynska Z, Schmalweiser A (2000) UV-Index for the public, EUR - COST 713 Action: UV-B forecasting. Luxembourg: Office for Official Publications of the European Communities.

Vikova M (2009) Methodology of measurement of chromic materials. In P. R. Somani (Ed), Chromic Materials, Phenomena and their Technological Applications (pp. 509-533). Maharashtra, India: Applied Science Innovations Private Limited.

Vikova M, Vik M (2009) Alternative UV sensors based on color-changeable pigments. Advances in Chemical Engineering and Science, 1(4): 224-230.

Xiaoming T (Ed.) (2001) Smart fibres, fabrics and clothing. Cambridge, UK: Woodhead Publishing. 